\title{
Plant-level Dynamic Optimization of Cryogenic Carbon Capture with Conventional and Renewable Power Sources
}

\author{
Seyed M. Safdarnejad \\ Brigham Young University \\ John Hedengren \\ Brigham Young University, john.hedengren@byu.edu \\ Larry Lin Baxter \\ Brigham Young University - Provo, larry_baxter@byu.edu
}

Follow this and additional works at: https://scholarsarchive.byu.edu/facpub

Part of the Chemical Engineering Commons

\section{Original Publication Citation}

http://www.sciencedirect.com/science/article/pii/S030626191500402X

\section{BYU ScholarsArchive Citation}

Safdarnejad, Seyed M.; Hedengren, John; and Baxter, Larry Lin, "Plant-level Dynamic Optimization of Cryogenic Carbon Capture with Conventional and Renewable Power Sources" (2015). Faculty Publications. 1689.

https://scholarsarchive.byu.edu/facpub/1689

This Peer-Reviewed Article is brought to you for free and open access by BYU ScholarsArchive. It has been accepted for inclusion in Faculty Publications by an authorized administrator of BYU ScholarsArchive. For more information, please contact ellen_amatangelo@byu.edu. 


\title{
Plant-level Dynamic Optimization of Cryogenic Carbon Capture with Conventional and Renewable Power Sources
}

\author{
Seyed Mostafa Safdarnejad ${ }^{\mathrm{a}}$, John D. Hedengren ${ }^{\mathrm{a}, *}$, Larry L. Baxter $^{\mathrm{a}}$ \\ ${ }^{a}$ Department of Chemical Engineering, 350 CB, Brigham Young University, Provo, UT \\ 84602, USA
}

\begin{abstract}
Increasing competitiveness of renewable power sources due to tightening restrictions on $\mathrm{CO}_{2}$ emission from fossil fuel combustion is expected to cause a shift in power generation systems of the future. This investigation considers the impact of the Cryogenic Carbon Capture ${ }^{\mathrm{TM}}$ (CCC) process on transitional power generation. The CCC process consumes less energy than chemical and physical absorption processes and has an energy storage capability that shifts the parasitic loss of the CCC process away from peak hours. The CCC process responds rapidly to the variation of electricity demand and has a time constant that is consistent with the intermittent supply from renewable power sources. The hybrid system of conventional and renewable power generation units and the CCC process are optimized in this investigation. The system under consideration consists of load-following coal and gas-fired power units, a CCC process, and wind generation. The objective is to meet the residential and CCC plant electricity demands while maximizing the operating profit. The results demonstrate that an average profit of $\$ 35 \mathrm{k} / \mathrm{hr}$ is obtained from this hybrid system over the selected days. The total electricity demand is best met using a combination of coal, gas, and wind power with grid-scale energy storage.
\end{abstract}

Keywords: Cryogenic Carbon Capture, Fossil-fueled power production,

\footnotetext{
*Corresponding author. Tel.: +1 801477 7341, Fax: +1 8014220151

Email addresses: safdarnejad@byu.edu (Seyed Mostafa Safdarnejad), john.hedengren@byu.edu (John D. Hedengren), larry_baxter@byu.edu (Larry L. Baxter) 
Renewable energy generation, Dynamic Optimization

\section{Introduction}

Electricity transmission is one of the main forms of energy delivery today. Different generation methods are being explored to supply increasing demand. According to the International Energy Agency (IEA) 1], electricity transmits

5 roughly $33 \%$ of the total energy worldwide. Over eighty percent of this electricity is generated from non-renewable sources [2]. According to the EPA [3, 58\% of global greenhouse gases are produced for energy supply, transportation, and industrial purposes. The same report also claims that $57 \%$ of the human-caused greenhouse emissions are attributed to carbon dioxide, which primarily comes from fossil fuels.

The US and other developed nations have reduced $\mathrm{CO}_{2}$ emissions in recent years through a combination of events, including a global recession, transformation from coal to natural gas in new power generation systems, increased automobile efficiency, and decreased miles driven [4, 5]. Furthermore, interest in renewable energy sources like solar and wind power continues to increase which further helps reduce the $\mathrm{CO}_{2}$ emissions. However, many renewable energy supplies are intermittent and have capacity factors that are small compared to thermal power generation units. Therefore, because a one megawatt (MW) wind or solar power unit cannot replace a $1 \mathrm{MW}$ thermal power unit, wind or solar power units must be integrated with thermal power units to develop a reliable power generation system.

There is a wide body of research on integrated power generation systems. Goransson et al. [6] presented a model to investigate the effect of large-scale wind and thermal power integration. The purpose of the investigation was to investigate the impact of wind power generation on the production strategies of thermal power production systems. They also considered the startup and turn down performance of the thermal units. However, spinning reserves must often be on standby due to the limited rate of startup and the possibility of decrease 
from an intermittent supply. Delarue et al. [7] studied the impact of wind power generation on the cost associated with electricity generation, fuel, and $\mathrm{CO}_{2}$ emission. They considered the unpredictability of wind speed forecast and proposed a wind forecasting method. The power plant was scheduled over a 24 hour horizon with forecasted wind power data to meet the demand with minimal cost. Hu et al. 8] developed a Solar Aided Power Generation (SAPG) system, using the traditional Rankine power cycle and solar heating. They concluded that SAPG is more efficient than both the solar thermal power systems and the conventional fuel-fired power cycles. Manenti et al. 9] developed a dynamic model for solar power plants with storage. The dynamic simulation optimized power generation and improved the net income of a concentrating solar power

40 plant. This optimization considered the market demand in real-time, storing superfluous energy, and using the stored energy when necessary. Powell et al. [10, 11. considered a solar thermal power plant integrated with a two-tank-direct thermal energy storage system. They found that the energy storage system led to a $64 \%$ increase in utilization of solar power with intermittent supply. Onar et

45 al. 12] studied the combination of wind, fuel cell, and ultra-capacitor systems for energy production. The fuel cell and ultra-capacitor systems worked as a backup for the variations in wind turbine power output to keep a reliable power production system. In the investigation, wind power was the main source of energy. It also powered an electrolyzer that produced hydrogen for the fuel cell during peak hours. In peak hours, when wind power was insufficient, the fuel cell and ultra-capacitor systems provided the required additional power.

Restrictions on $\mathrm{CO}_{2}$ emissions from fossil fuel combustion and increased use of intermittent renewable energy resources must be addressed for power generation systems in the future 13 . Thus, it is critically important to study 55 the impact of $\mathrm{CO}_{2}$ mitigation processes on power generation systems. Kang et al. 13] studied an integrated system of energy production consisting of a coal plant, a wind power facility, and a temperature-swing $\mathrm{CO}_{2}$ capture unit [13]. A natural gas combustion turbine and heat recovery steam generator supplied heat for $\mathrm{CO}_{2}$ capture. The turbine also supplied supplemental electricity when 
required. The study also considered demand response in the form of storing $\mathrm{CO}_{2}$-rich amine solution during peak demand. They concluded that with an optimized operation, $20 \%$ more profit is obtained compared to a heuristic procedure. Belaissaoui et al. [14] explored the $\mathrm{CO}_{2}$ capture challenges for a gas turbine plant. The low concentration of $\mathrm{CO}_{2}$ in a gas turbine power plant led 65 them to consider membrane separation for $\mathrm{CO}_{2}$ capture. It was found that the overall energy requirement is less than $205 \mathrm{kWh} /$ ton $\mathrm{CO}_{2}$ with a highly selective membrane. Chalmers et al. [15] studied the flexibility added to power plants retrofitted with $\mathrm{CO}_{2}$ capture by operating under different scenarios. They considered a post-combustion capture process. The goal of this investigation was to maximize profit by choosing the operation pattern in response to electricity market prices. The scenarios that are considered are: (1) power plant shut down; (2) using a $\mathrm{CO}_{2}$ capture system; and (3) bypassing the $\mathrm{CO}_{2}$ capture system. Cohen et al. [16, 17, 18, considered the flexible operation of a $\mathrm{CO}_{2}$ capture unit integrated with a fossil-fueled power plant. They used an aminebased $\mathrm{CO}_{2}$ capture process with the objective of maximizing the profit of the hybrid system in response to electricity price volatility (incorporating spikes in the power price). In comparison to a similar system without the spikes in power price [19], flexible operation of the $\mathrm{CO}_{2}$ removal created higher operating profit. They also evaluated the profitability of two flexible configurations 80 for the operation of $\mathrm{CO}_{2}$ removal system under three 20-year $\mathrm{CO}_{2}$ price paths and compared them with the operation of inflexible $\mathrm{CO}_{2}$ removal. Chalmers et al. 20] studied the impacts of post-combustion capture on transient performance of coal-fired power plants. They also differentiated between plants with $\mathrm{CO}_{2}$ capture and without $\mathrm{CO}_{2}$ capture in the load-following capability, and recommended considering some constraints to power plant start-up due to the post-combustion capture. Gerbelov et al. [21] explored the performance, cost impacts, and feasibility of retrofitting an amine based post-combustion capture method for existing power plants. Two sub-critical coal power plants and two natural gas combined cycle plants were considered in the investigation. Net 90 plant efficiency loss of the coal-fired and gas-fired power plants were found to be 
12 and $8 \%$, respectively, based on the higher heating value (HHV). The capital cost of both natural gas-fired and coal-fired power plants was explored and it was found that natural gas-fired power plants require less capital costs because of lower $\mathrm{CO}_{2}$ concentrations in the flue gas. The investigation also examined the effect of fuel price on the breakeven point (the point at which the cost of electricity is equal for plants with and without Carbon Capture and Storage (CCS) at a set price of $\mathrm{CO}_{2}$ emission). Cormos et al. 22 assessed the techno-economic and environmental aspects of power generation for an Integrated Gasification Combined Cycle (IGCC) power plant with and without CCS. A pre-combustion method using gas-liquid absorption in physical solvents (Selexol) was used for carbon capture. The study investigated IGCC with CCS from different aspects, including plant capital cost, operational and maintenance cost, Levelized Cost of Electricity (LCOE), and $\mathrm{CO}_{2}$ capture. Cormos et al. [23] explored integration of CCS with both Pulverized Coal (PC) power plants and IGCC plants. A post-combustion carbon capture method was used for PC plants; however, for IGCC power plants, a pre-combustion method was used. It was found that energy penalty for introduction of CCS, on the net energy percentage basis, is 8-9 \% for PC power plants and about $7 \%$ for IGCC plants. Some studies also considered using renewable energy sources to provide the energy requirement of $\mathrm{CO}_{2}$ capture process or to efficiently utilize $\mathrm{CO}_{2}$ produced from power plants to adopt more renewable energy. Khorshidi et al. 24] explored using auxiliary units fueled by biomass to compensate for the energy loss of the $\mathrm{CO}_{2}$ capture process. They considered a combined heat and power ( $\mathrm{CHP}$ ) production unit that used biomass as the fuel and found that a $\mathrm{CO}_{2}$ price of at least $\$ 55 /$ tonne $\mathrm{CO}_{2}$ or a biomass price of less than $1 \$ / \mathrm{Gj}$ is required to cost-effectively capture $\mathrm{CO}_{2}$ from both the coal plant and auxiliary biomass CHP unit. Mohan et al. 25] considered an integrated system of an IGCC power plant and an enhanced geothermal system (EGS). The purpose of the study was to extract geothermal heat by using $\mathrm{CO}_{2}$ produced from an IGCC plant as the heat transfer fluid. In addition to the power produced from geothermal energy in an organic Rankine cycle (OCR), power was also produced by expansion of $\mathrm{CO}_{2}$ in a high pressure 
turbine before being re-injected to the reservoir. For a sample case, it was shown that such a hybrid system was able to recover $74 \%$ of the energy consumption of the carbon capture and sequestration.

Although various methods have been developed for $\mathrm{CO}_{2}$ capture, the major drawback of most of $\mathrm{CO}_{2}$ removal systems is the parasitic energy load. Jensen et al. 26] stated that the average energy consumption of using oxy-combustion, absorbents, adsorbents, or membranes for $\mathrm{CO}_{2}$ removal is $1.69,1.72,3.39$, and $1.3 \mathrm{MJ}_{\mathrm{e}} / \mathrm{kg} \mathrm{CO}_{2}$, respectively. The Cryogenic Carbon Capture (CCC) process, currently under development at Sustainable Energy Solutions (SES) 27, is another technology for $\mathrm{CO}_{2}$ removal and is less energy intensive compared to the aforementioned capture systems (an average of $0.98 \mathrm{MJ}_{\mathrm{e}} / \mathrm{kg} \mathrm{CO}_{2}$ ). This process has some configurations that store energy in the form of liquefied natural gas (LNG). This capability manages the energy loss of $\mathrm{CO}_{2}$ removal by using stored refrigerant to drive the process during peak demand, transferring the reduced parasitic load to the grid to help meet demand, and regenerating the refrigerant during low-demand periods. In addition, the rapid-load-change capability of the CCC enables conventional power generation systems to integrate more easily with renewable intermittent power sources [27. As renewable energy sources become a larger portion of the energy market, fossil-fueled generators that were originally designed for baseline power production have to operate on a load-following basis, which results in increased emissions and operational costs [28. Thus, by adopting more renewable energy sources into the power grid, the significance of rapidly responding to large fluctuations with energy storage becomes critical to maintaining a reliable and cost-effective electric grid. Detailed analyses of plant and process responses to these transient systems are underway elsewhere [27, 29, 26]. This investigation considers the grid-level responses of CCC-equipped systems. Most of the research on integrated systems of power generation and carbon mitigation have only considered steady-state simulations. With steady-state simulation, the transient behavior of the intermittent power sources and energy storage are neglected; however, with transient optimization, time-shifting of the parasitic load of the carbon mitigation process can be consid- 
ered, which can help reduce the operating cost. Thus, the dynamic optimization of an integrated system including conventional and renewable power plants with energy storage versions of the CCC process is considered in this investigation. The proposed system is able to meet the total electricity demand while reducing $\mathrm{CO}_{2}$ emissions by $90 \%$ with $100 \%$ utilization of the available wind energy.

This paper is divided into five sections; in the first section, the CCC process and the associated energy storage capability are briefly discussed. Then, the basic framework for the simulation and optimization of the integrated system is presented. Next, an example case study is discussed to demonstrate the concept of peak-shaving of the electricity demand by using an energy storage system. Then, basic assumptions of the integrated systems of the power sources and CCC are presented. Finally, simulation results for the integrated system are discussed. The results demonstrate that with the hybrid system of power generation and carbon capture, an average profit of $\$ 35 \mathrm{k} / \mathrm{hr}$ is obtained.

\section{Cryogenic Carbon Capture (CCC)}

As mentioned previously, the CCC process with energy storage has rapid load change capability; this can help integrate renewable intermittent supplies with smart power grids. The CCC process is a retrofit, post-combustion technology that captures $\mathrm{CO}_{2}$ in the flue gas through desublimation. The resulting solid is separated from the remaining light gases. Solid $\mathrm{CO}_{2}$ is then melted, pressurized, and transported to underground containment wells [27, 29]. The CCC process requires two refrigeration loops that consume most of the energy in running the compressors. However, refrigerant can be generated during non-peak hours and stored in insulated vessels that save the refrigerant for peak hour usage, thereby replacing the compressor energy with the stored refrigerant. This causes the refrigerant production rate to decrease during peak hours, which decreases the energy demand required by the CCC for as long as the stored refrigerant is available. Therefore, more power is available during peak hours relative to the baseline coal boiler rated capacity. In this investigation, storage of only one 
of the refrigerants is considered as it provides more energy during the recovery mode. The refrigerant considered for this purpose is LNG, although others could be selected. In addition, during the energy recovery mode of the CCC, a gas turbine can provide more power through the combustion of a fraction of the LNG after it goes through the CCC process and is converted to natural gas.

The LNG generation and storage cycle primarily involves compressors and heat exchangers; therefore, the storage/recovery or load changing response time is fast (seconds) compared to those of the steam boilers (hours). The faster energy storage response time is well matched to intermittent sources like wind turbines. Therefore, this energy storage system enables the steam boiler to follow rapidly changing loads. Storage capacity of LNG vessels also allows scaling from the proposed energy storage to large-scale systems. A more in-depth analysis of CCC can be found at [27, [29, 30, 31].

\section{Optimization Framework}

The general model framework used in this investigation is shown by Eq. (1).

$$
\begin{array}{r}
0=f\left(\frac{\delta x}{\delta t}, x, y, p, d, u\right) \\
0=g(x, y, p, d, u) \\
0 \leq h(x, y, p, d, u)
\end{array}
$$

where $x$ is a set of dependent variables, $y$ is a set of control variables, $p$ is a set of parameters, $d$ is a set of disturbance values, and $u$ is a set of control moves or inputs. The functions $f, g$, and $h$ represent residuals, output function, and inequality constraints, respectively. Variables can be continuous, binary, or integer values. The initial values of the variables are defined based on the nature of the system. Both differential and algebraic equations can be used in the general form of Eq. (1).

The form of the objective function used in this investigation is shown in Eq. (2) and is related to the nonlinear dynamic optimization with an $\ell_{1}$-norm 
common squared error norm is that it allows for a dead-band, permits explicit prioritization of multi-objective problems, and adds only linear terms to the problem. The latter advantage of using $\ell_{1}$-norm is especially important as it can be easier to numerically solve the problem [32, 33, 34].

$$
\begin{gathered}
\min \phi=w_{h i}^{T} \cdot e_{h i}+w_{l o}^{T} \cdot e_{l o}+y_{m}^{T} \cdot c_{y}+u^{T} \cdot c_{u}+\Delta u^{T} \cdot c_{\Delta u} \\
\text { s.t. } \quad 0=f\left(\frac{\delta x}{\delta t}, x, y_{m}, p, d, u\right) \\
0=g\left(x, y_{m}, p, d, u\right) \\
h\left(x, y_{m}, p, d, u\right) \geq 0 \\
\tau_{c} \frac{\delta y_{t, h i}}{\delta t}+y_{t, h i}=S P_{h i} \\
\tau_{c} \frac{\delta y_{t, l o}}{\delta t}+y_{t, l o}=S P_{l o} \\
e_{l o} \geq\left(y_{t, l o}-y_{m}\right) \\
e_{h i} \geq\left(y_{m}-y_{t, h i}\right) \\
\end{gathered}
$$

where the nomenclature for Eq. 20 is found in Table 1

The variables $c_{y}, c_{u}, c_{\Delta u}$ serve as tuning factors to achieve a desired outcome. The set of equations in Eq. (2) is implemented in APMonitor Modeling Language [35]. More information about how to implement an optimization in APMonitor Modeling Language can be found in 32 .

As previously mentioned, differential equations can also be used in the general form of Eq. (1). APMonitor uses the method of orthogonal collocation 
Table 1: Nomenclature for general form of the objective function with $\ell_{1}$-norm formulation

\begin{tabular}{|c|l|}
\hline$\phi$ & objective function \\
\hline$y_{m}$ & model values $\left(y_{m, 0}, \ldots, y_{m, n}\right)^{T}$ \\
\hline$y_{t, h i}, y_{t, l o}$ & trajectory dead-band for target values \\
\hline$w_{h i}, w_{l o}$ & penalty factors outside trajectory dead-band \\
\hline$c_{y}, c_{u}, c_{\Delta u}$ & cost of variables $y, u$, and $\Delta u$, respectively \\
\hline$u, x, p, d$ & inputs $(u)$, states $(x)$, parameters, and disturbances $(d)$ \\
\hline$f, g, h$ & equation residuals $(f)$, output function $(g)$, and inequality \\
\hline$\tau_{c}$ & time constant of desired controlled variable response \\
\hline$e_{l o}, e_{h i}$ & slack variable below or above the trajectory dead-band \\
\hline$S P_{l o}, S P_{h i}$ & lower and upper bounds to final set point dead-band \\
\hline
\end{tabular}

on finite elements 32] to convert differential algebraic equations (DAE) to a nonlinear programming (NLP) form. To accomplish this, a coefficient matrix relates the derivative values to the non-derivative values over a time horizon with continuity at adjacent collocation intervals. The matrix converts the differential equations to algebraic expressions [32]. The aforementioned algebraic expressions and equations represented in Eq. (2) are solved using either an active set solver (APOPT) [36, 37] or an interior point solver (IPOPT) 38].

\section{Example Case Study for Energy Storage Concept}

In this section, an example case study is developed to demonstrate the energy storage concept. The main power generation unit output is assumed to be constant in this case. Excess energy is stored during off-peak hours or when more energy is available than the required electricity demand. The stored energy is used during peak hours to meet the higher electricity demand. The objective is to minimize the power production unit output. This goal is obtained by efficiently using the energy storage system to meet the cyclical demand cycle that is typical for a grid-scale power distribution system. The assumed demand 
profile has a periodic form that is typical for both industrial and residential areas. As energy storage and energy recovery are not coincident, slack variables are used in this example case to help the optimizer switch between energy storage and energy recovery. The time horizon considered for this simplified case is 24 hours with 20 minute time discretization.

The equations used to model this simplified case are given below. These equations represent a simple power dispatching system and demonstrate the concept of peak-shaving of the electricity demand by using an energy storage system.

$$
\begin{gathered}
\min P \\
\text { s.t. } \quad \frac{\delta I}{\delta t}=S \cdot \epsilon-R \\
S=P-D+S_{2} \\
R=D-P+S_{1} \\
P-D=S_{1}-S_{2} \\
S_{1}, S_{2} \geq 0 \\
S_{1} \times S_{2} \leq 0 \\
P+R-S \geq D \\
I \geq 0
\end{gathered}
$$

where $P, D, S, R$ and $I$ represent power production, electricity demand, stored energy, recovered energy, and inventory of stored energy, respectively. $S_{1}$ and 
$S_{2}$ are slack variables to help switch between energy storage and energy recovery and are constrained to be positive. The efficiency loss during storage of energy is represented by $\epsilon$. Eq. 3a defines the objective function. Eq. (3b) represents the energy balance for the energy storage system. Eqs. (3c) and (3d) represent the magnitude of the stored and recovered energy, and Eq. (3e) defines the magnitudes of $S_{1}$ and $S_{2}$. Eqs. (3f) and (3g) ensure that storage and recovery modes do not operate simultaneously (either $S_{1}$ or $S_{2}$ or both should be zero during the time horizon). Eq. (3h guarantees that power supply from power production and energy recovery, with consideration of the storage of energy during off peak hours, is always greater than the electricity demand. Eq. (3i) ensures that energy inventory is always greater than or equal to zero. According to the optimization framework proposed previously, Eq. (3c) to (3e) serve as the equality constraints while (Eq. (2c) ) and Eq. (3f) to (3i) serve as the inequality constraints (Eq. (2d)).

When $S_{2}$ is zero, $S_{1}$ is equal to $P-D$, according to Eq. (3e). Consequently, $255 S$ equals excess energy $(P-D)$ based on Eq. (3c) and $R$ equals zero in agreement with Eq. (3d). Thus, this case represents the storage mode, and the inventory of the storage system increases according to Eq. (3b). When $S_{1}$ is zero, $S_{2}$ becomes $D-P$ from Eq. (3e). Consequently, $R$ equals $D-P$ from Eq. (3d) and $S$ equals zero. Thus, this case represents the recovery mode, and the inventory of the storage system decreases according to Eq. 3b.

Results of the simplified case are presented in Figure 1. As shown in the figure, when power generation is more than the required electricity demand, energy is stored and the energy inventory of the storage system increases. When electricity demand is greater than the power production, energy is recovered from storage and energy inventory in the storage system decreases. Slack variables show consistent trends with these findings. This example case demonstrates the energy storage optimization concept used in the more detailed case of power production with CCC. 

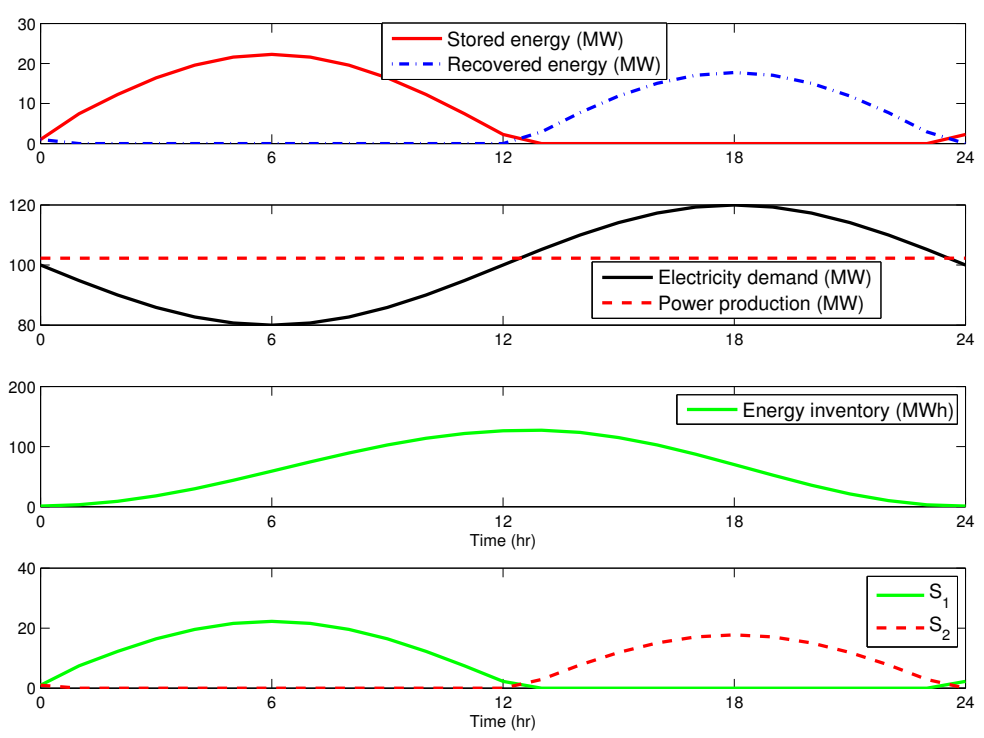

Figure 1: Results for the simplified case of energy storage

\section{Modeling of CCC Process with Power Production Systems}

This section, outlines the basic concepts for a more in-depth case of optimization of the CCC process integrated with the power production units, as illustrated in Figure 2

In this investigation, the power output from wind power stations in the SP-15 trading hub in southern California, USA is combined with the power production

from a steam boiler. This study assumes that wind power only contributes up to $10 \%$ of the integrated residential demand over the time horizon. Thus, total actual hourly wind power data from the SP-15 trading hub is uniformly scaled down such that integrated wind power over the time horizon is approximately $10 \%$ of the integrated residential demand used in this investigation. The steam boiler is the main source of energy production in this investigation. However, steam boilers used to produce power have slow responses to changes in electricity demand (2-3 hour) and wind power is not always sufficiently available (Figure 


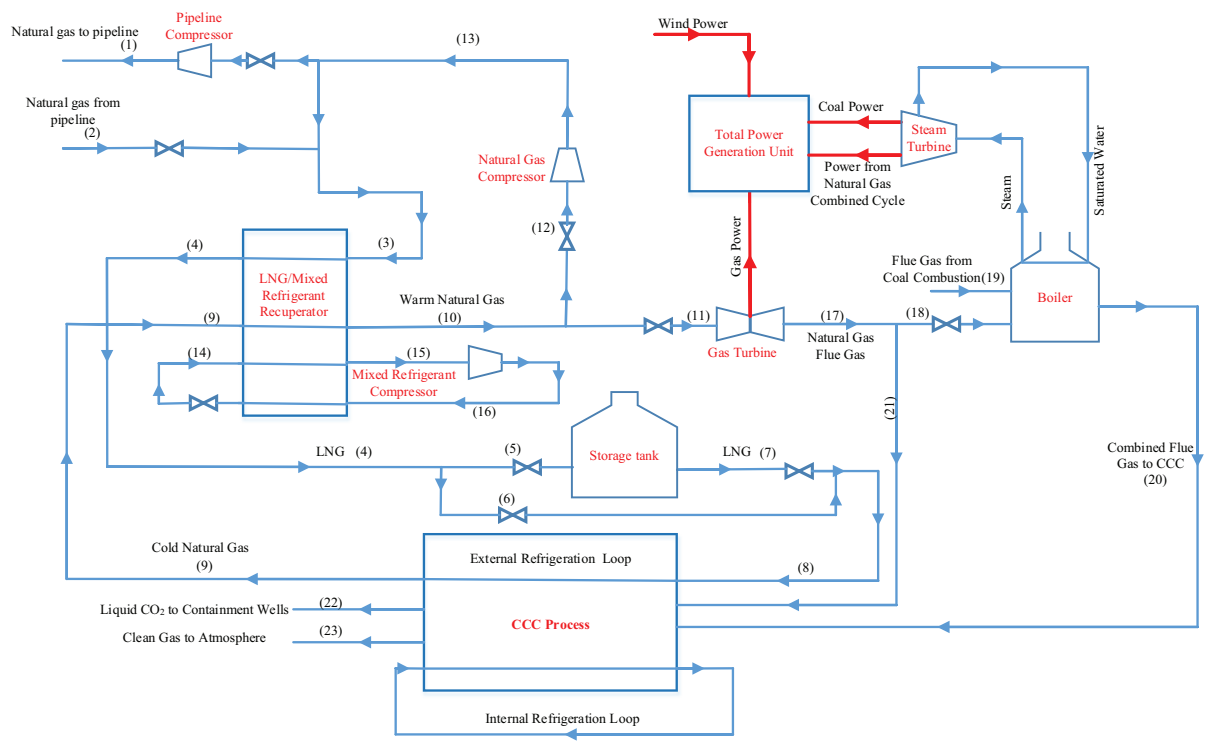

Figure 2: Schematic configuration of the integrated system of power generation and CCC process

3). The lack of wind power is compensated by the CCC energy storage system. During energy recovery, excess natural gas is produced from this system. In this configuration, a gas turbine is coupled to the CCC system as described in [30, 31, 39]. This turbine has a faster response time (5-10 minutes) than the boiler. The hot gas outlet from this turbine is combined with the coal gases in the boiler convection pass, which gives the turbine the efficiency of a combinedcycle system. Thus, a fraction of the flue gas from gas turbine (stream 18 in Figure 2 is directed to the steam boiler to produce steam for power generation and the rest of it (stream 21 in Figure 2) is directed to the CCC plant. Despite the fact that the flue gases produced from coal and gas combustion have different compositions, it is assumed that the flue gas exhausts from both streams are treated with the same CCC process for simplicity (Figure 2). One approach to operating with only one boiler for both flue gas exhausts is to consider a recirculation cycle after the gas turbine, in which part of the natural gas flue gas is recirculated and introduced back into the compressor inlet. As a result, 


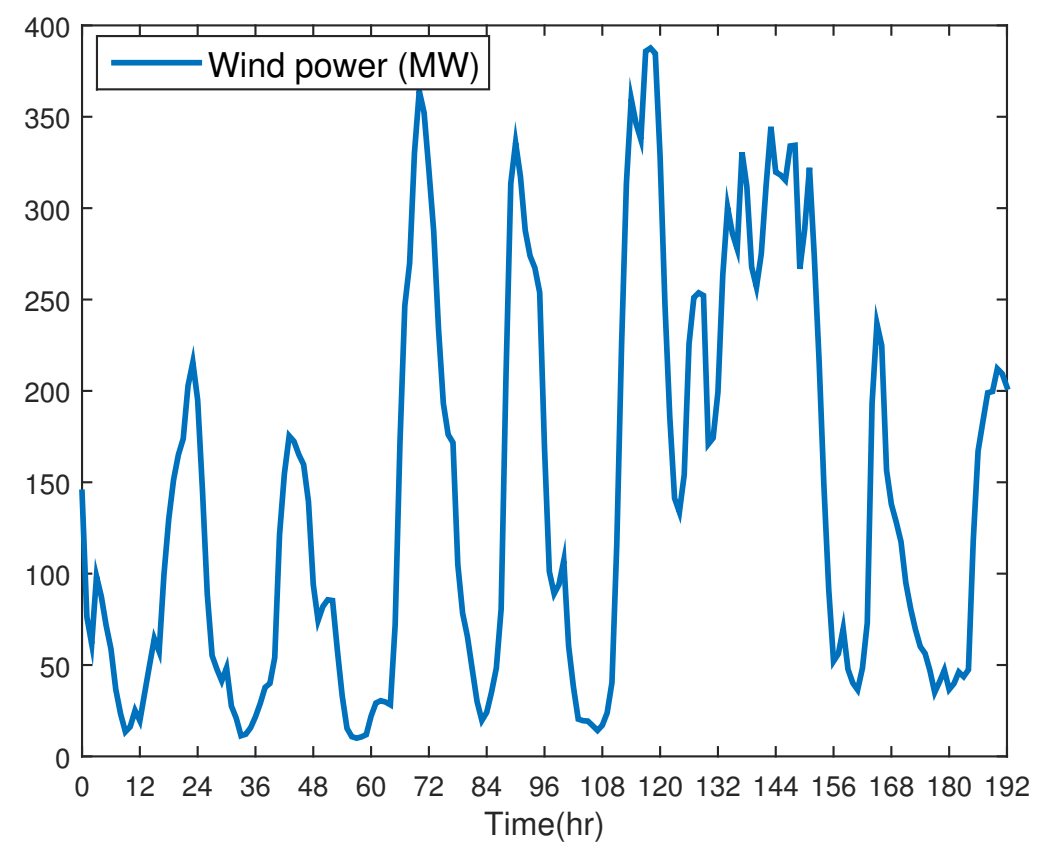

Figure 3: Actual wind power data for the period between September 13, 2014 and September 20, 201443 .

the $\mathrm{CO}_{2}$ concentration of the natural gas flue gas directed to the boiler can be increased to the coal flue gas $\mathrm{CO}_{2}$ level [40, 41, 42]. The recirculation concept is the subject of future work and is not included in this contribution.

As mentioned in Section 2, an LNG tank is used as energy storage. To better represent the storage and recovery modes of operation, a stream (stream 6 in Figure 2 bypasses the tank. The storage tank allows natural gas to be imported from the pipeline and converted to LNG during periods with low electricity prices. The fraction of the produced LNG required to run the CCC process during off peak hours directly flows toward the process through the bypass stream. The excess LNG flows to the tank inlet (stream 5 in Figure 2). During peak hours or periods with expensive electricity prices, LNG is supplied from two sources: (1) the storage tank (2) the liquefaction of the recirculating natural gas. The LNG directed to the CCC process (stream 8 in Figure 2) is 
vaporized so that heat is removed from the process. The natural gas coming from CCC (stream 9 in Figure 2 has sufficient cooling potential to be used to liquefy a fraction of the recirculating natural gas (stream 13 in Figure2). Thus, by passing the cold natural gas coming from the CCC (stream 9 in Figure 3152 through the LNG/mixed refrigerant (MR) recuperator, heat is recovered from the warm recirculating natural gas (stream 13 in Figure 22. Therefore, a fraction of the required LNG for running the CCC process is supplied from the recirculating natural gas. The rest of the required LNG is supplied from the tank (stream 7 in Figure 2). Thus, LNG production is ramped down during peak hours by using an LNG storage tank. At any given time, either the storage or recovery mode is always in operation. The combination of the LNG storage tank, LNG/MR recuperator, mixed refrigerant compressor, and natural gas compressors used in LNG production is referred to as the LNG plant.

A fraction of the natural gas that comes from the LNG/MR recuperator 325 (stream 10 in Figure 2) can be combusted in a gas turbine for power production (stream 11 in Figure 2), depending on the time of day. During periods with low power prices, a significant fraction of the natural gas is recycled to the LNG/MR recuperator (stream 13 in Figure 2); when electricity is expensive, a fraction of the natural gas (stream 11 in Figure 2) is combusted in a gas 330 turbine to compensate for loss of the CCC and to meet the LNG plant demands. The rest of the natural gas is recirculated to the LNG/MR recuperator. Thus, the energy loss of the $\mathrm{CO}_{2}$ removal system is compensated by ramping down the mixed refrigerant compressor and combusting a fraction of the natural gas coming from the CCC process. However, it should be emphasized that although the natural gas compressor is in operation during both peak and off peak hours, the parasitic loss of the mixed refrigerant compressor decreases in peak hours or when electricity is expensive.

Another option to decrease energy consumption in the LNG plant is to export a fraction of the recirculating natural gas to the pipeline (stream 1 in Figure 340 2) and avoid processing it in the LNG/MR recuperator. However, the pressure of the natural gas before the natural gas compressor is approximately 11 bar 
and the pressure of the pipeline natural gas is approximately 55 bar; thus, the pressure should be increased to pipeline pressure if natural gas is to be exported. A pressure increase is implemented in two stages in this study: (1) in the natural gas compressor (from 11 to 37 bar) and (2) in the pipeline compressor (from 37 to 55 bar). The pressure increase in the natural gas compressor should always occur, even if natural gas is not exported to the pipeline. However, the pressure increase in the pipeline compressor does not significantly increase the parasitic loss of the plant (approximately 3.2 MW). The exported natural gas also offers a lower $\mathrm{CO}_{2}$ concentration and is more pure than the imported natural gas because of the purification that occurs through the refrigeration cycle. The natural gas export is a cost saving measure for the integrated system as it recovers part of the operating costs for unused natural gas. However, the price value of the more pure natural gas is the same as the natural gas from the pipeline in this investigation and is not awarded extra credit for the purification. This is mainly because of the unwillingness of the utility contractors to buy back natural gas at a higher price. In other words, if natural gas is to be simultaneously purchased or sold to utility contractors, the sale and purchase price will be equal. This study assumes constant natural gas price. Decisions about whether natural gas should be exported or imported at each time step are based on the economic evaluation of the objective function.

\subsection{Model inputs}

A residential electricity demand profile is used as the actual hourly integrated data for San Diego, USA, for the period between September 13, 2014 and

365 September 20, 2014. These data give the peak electricity demand of the year in the area [44. Because this study represents the integration of the CCC process with only one power generation unit, the electricity demand data is scaled to have a maximum residential demand of $2000 \mathrm{MW}$. Integrating a power grid system (without needing to scale the demand) with the CCC process is the sub-

370 ject of another study [45] that also considers grid-scale stability analysis. The assumed electricity demand profile is typical for many residential areas and is 
shown in Figure 4. The average price of electricity for the same period in 2014 for California is also shown in Figure 446]. It is seen from Figure 4 that periods with high electricity demand also have more expensive power price. Wind data shown in Figure 3 are based on the actual wind power data for the same period of time in 2014 for southern California [43. It should be mentioned that the assumed residential electricity demand and wind power curves are for one of the possible worst-case scenarios (summer days) when the electricity demand reaches the maximum of the year in the assumed zone in California in 2014. The trend of the power price in the period of time considered in this investigation shows less spikes than the rest of the year [46. More severe fluctuations are expected to improve the economic justification for energy storage with the CCC. A typical period was therefore selected over an extended time frame without inflating the benefits. The overall efficiencies of the coal and gas-fired power plants are $36.8 \%$ and $50.2 \%$, respectively, based on higher heating values (HHV) [47.

The coal composition used in this work is that of the subbituminous Wyoming Powder River Basin coal as given in the Integrated Environmental Control Module (IECM) [48. Delivered coal price for Wyoming Powder River Basin is assumed to be $\$ 12.65 /$ ton as of March 2014 [49. Composition of the imported natural gas is also taken from IECM [48]. Natural gas price is the US national average price of 2014 for the electric power sector ( $\$ 5.19$ per thousand cubic feet) [50]. Long-term contracts can be secured to reduce the variability of fuel costs from sources such as natural gas.

The work of compression for the stream entering the natural gas compressor (stream 12 in Figure 2) is $0.051 \mathrm{~kW}$ per $\mathrm{kg} / \mathrm{hr}$ of the inlet stream. The work of compression for the mixed refrigerant entering the compressor (stream 15 in Figure 2 is $0.077 \mathrm{~kW}$ per $\mathrm{kg} / \mathrm{hr}$ of the inlet stream. These figures are based on the results obtained previously [27, 29]; it was assumed that only the integrated system of power generation and CCC is in operation and energy storage, stream leading to the gas turbine (stream 11 in Figure 2) and streams imported or exported to the pipeline (streams 2 and 1, respectively) are not considered. The 


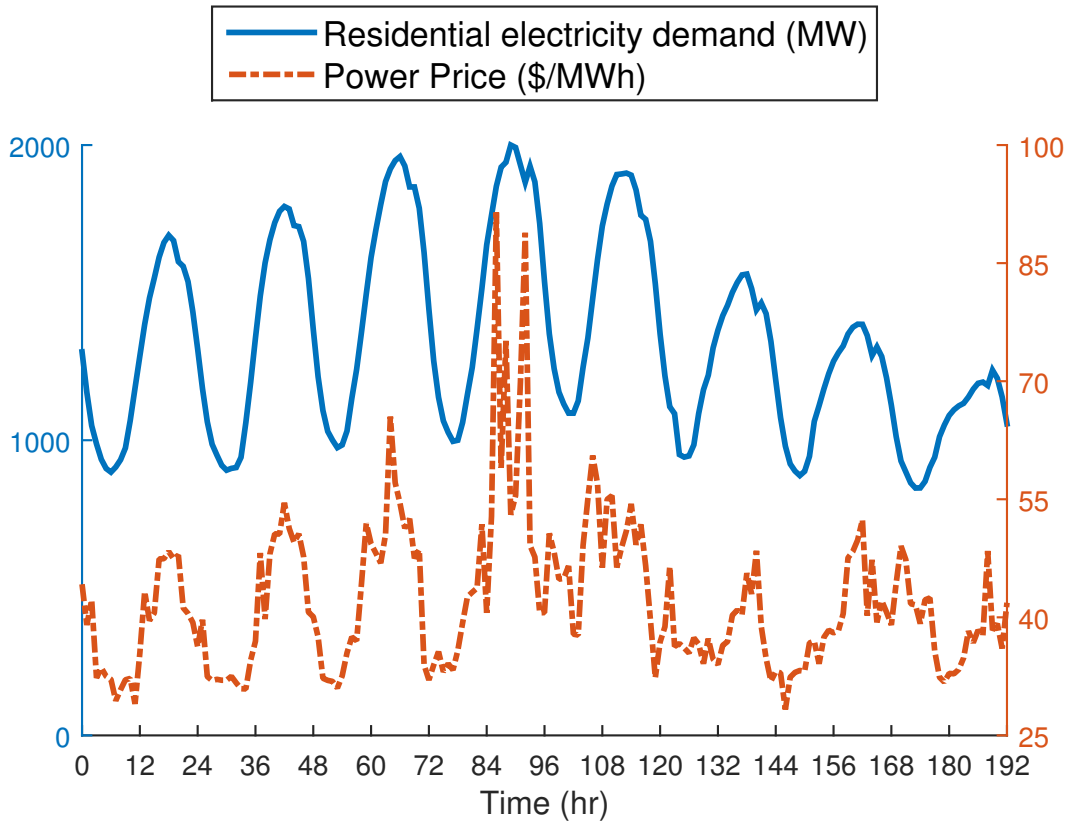

Figure 4: Actual electricity demand for San Diego, USA, and average power price for California for the period between September 13, 2014 and September 20, 2014 [44, 46].

work of compression of the pipeline compressor in Figure 2 is also $0.01 \mathrm{~kW}$ per $\mathrm{kg} / \mathrm{hr}$ of the inlet stream.

The electricity demand of the CCC plant is dependent on the flow rate of the flue gas that enters the plant. The flue gas comes from both the coal-fired power plant and the gas turbine. However, the CCC plant electricity demand is constant per unit mass of the captured $\mathrm{CO}_{2}$. According to prior simulation results of the CCC plant 27, 29, the CCC plant electricity demand is 0.389 and 0.428 GJ per tonne of the captured $\mathrm{CO}_{2}$ from the flue gas coming from coal power plant and gas turbine, respectively. These values are obtained based on $90 \%$ capture of $\mathrm{CO}_{2}$ from the flue gas coming from both coal-fired and gasturbine power plants. In addition, the flue gas flow rate varies according to the power output. Therefore, the CCC plant electricity demand equals the power outputs of the coal and gas-fired power generations systems, each multiplied 
by the amount of CCC power consumed per unit of power output. The same idea applies for the LNG required to run the CCC process; the amount of LNG necessary to process the flue gas coming from the coal and gas-fired power generation systems is proportional to the net coal and gas power outputs. The LNG needed to process the coal and gas flue gases is 856 and $685 \mathrm{~kg}$ per 1000 $\mathrm{kg}$ captured $\mathrm{CO}_{2}$, respectively. Table 2 summarizes the input parameters used in this investigation.

To consider the dynamic response of base control components of the integrated system, first-order differential equations are applied to limit equipment response times. These components include power production from a steam boiler and a natural gas intake system, which have 2 hour and 5 minute time constants, respectively. A time constant represents the amount of time required to achieve $63 \%$ of the way to a final target value when there is a step change from a steady-state starting condition. Dynamic mass conservation equations are also applied, when necessary. The dynamic mass balance is especially important in representing the storage tank balance equation. It is assumed that the LNG tank is well insulated; thus, the energy exchange between the tank and environment is ignored. An energy balance of the LNG/MR recuperator is also considered.

435 5.2. Objective function

The objective is to maximize the profit obtained from the integrated system of power generation, CCC, and LNG plants, while meeting the residential, CCC, and LNG plants electricity demands. An equation describing the profit is presented in Eq. (4). Profit is in units of $\$ / \mathrm{hr}$.

$$
\text { Profit }=\left(D_{R}-D_{L N G}-D_{C C C}-D_{P C}\right) P^{E}-\left(N_{I}-N_{E}\right) P^{N}-C P^{C}
$$

440

where $D_{R}, D_{L N G}, D_{C C C}, D_{P C}$ and $P^{E}$ represent residential demand (MW), LNG plant demand (MW), CCC plant demand (MW), pipeline compressor demand (MW), and power price $(\$ / \mathrm{MWh})$, respectively. $N_{I}, N_{E}, P^{N}, C$, and $P^{C}$ 
Table 2: Summary of the input parameters

\begin{tabular}{|c|c|}
\hline Coal power plant capacity (MW) & 1800 \\
\hline Gas turbine capacity (MW) & 1000 \\
\hline Maximum combined power production from gas turbine (MW) & 190 \\
\hline Maximum wind power data (MW) & 390 \\
\hline Maximum residential electricity demand (MW) & 2000 \\
\hline Overall efficiency of coal power production & $36.8 \%$ \\
\hline Overall efficiency of gas power production & $50.2 \%$ \\
\hline $\begin{array}{l}\text { Work of compression for natural gas compressor }(\mathrm{kW} /(\mathrm{kg} / \mathrm{hr} \text { inlet })) \text { or } \\
\left(\mathrm{GJ} / \text { tonne } \mathrm{CO}_{2}\right)\end{array}$ & $0.051(0.1656)$ \\
\hline $\begin{array}{l}\text { Work of compression for mixed refrigerant compressor }(\mathrm{kW} /(\mathrm{kg} / \mathrm{hr} \text { inlet })) \\
\text { or }\left(\mathrm{GJ} / \text { tonne } \mathrm{CO}_{2}\right)\end{array}$ & $0.077(0.1818)$ \\
\hline Work of compression for pipeline compressor $\mathrm{kW} /(\mathrm{kg} / \mathrm{hr})$ & 0.01 \\
\hline $\begin{array}{l}\text { Electricity demand of the } \mathrm{CCC} \text { for treatment of the flue gas (coal combus- } \\
\text { tion)(GJ/(tonne } \mathrm{CO}_{2} \text { captured)) }\end{array}$ & 0.389 \\
\hline $\begin{array}{l}\text { Electricity demand of the CCC for treatment of the flue gas (gas combus- } \\
\text { tion) }\left(\mathrm{GJ} /\left(\text { tonne } \mathrm{CO}_{2} \text { captured }\right)\right)\end{array}$ & 0.428 \\
\hline LNG demand to process the coal flue gas $\left(\mathrm{kg} /\left(\right.\right.$ tonne $\mathrm{CO}_{2}$ captured $\left.)\right)$ & 856 \\
\hline LNG demand to process the gas flue gas (kg/(tonne $\mathrm{CO}_{2}$ captured $\left.)\right)$ & 685 \\
\hline Coal price $(\$ /$ ton $)$ & 12.65 \\
\hline Natural gas price $\left(\$ / 1000 \mathrm{ft}^{3}\right)$ & 5.19 \\
\hline
\end{tabular}


represent natural gas flow rate imported to the plant $(\mathrm{kg} / \mathrm{hr})$, natural gas flow rate exported to the pipeline $(\mathrm{kg} / \mathrm{hr})$, natural gas price $(\$ / \mathrm{kg})$, coal flow rate $(\mathrm{kg} / \mathrm{hr})$, and coal price $(\$ / \mathrm{kg})$, respectively. To avoid variation in a stream's volume due to the pressure change in the integrated system, all of the streams are represented on a mass unit basis. This investigation focuses on operating costs, though levelized capital costs could be introduced to the cost functions if investment decisions are to be included.

It is important to note that the electricity demand profile is an input to the model and is not a decision variable. Revenue obtained from selling the electricity (first term in the right hand side of Eq. (4) ) is constant in all scenarios considered in Section 6. Thus, the optimizer actually tries to optimize the profit function from the remaining expressions in Eq. 44. Using the electricity demand in the profit function, however, would provide a comparison basis for the profitability of the hybrid system.

Coal and gas consumption rates, imported and exported natural gas flow rates, and tank inlet flow rate vary to find the maximum profit. In this investigation, the variation of boiler thermal load is restricted to be less than $7 \%$ per minute for a supercritical power plant working in $45-100 \%$ range of its capacity, according to 51 .

A time horizon of eight days with one hour time increments is considered for profit maximization. By removing the boundary conditions, the performance of the three middle days represents an infinite time horizon. Because of the complexity of the model and the large number of variables and equations to be solved, initialization strategies are applied to speed up the computational time of the simulations 52 .

\subsection{Constraints}

There are several constraints applied in this optimization problem. First, power production from a gas turbine is assumed to be limited to $50 \%$ of the maximum residential electricity demand (2000 MW in this case). Thus, the maximum power that can be produced from the gas turbine is $1000 \mathrm{MW}$. This 
constraint helps develop an efficient storage of LNG to be used in peak hours. The fraction of the flue gas exhaust from natural gas combustion that is used in the combined cycle power production (stream 18 in Figure 2) is limited to a flow rate equivalent to a power output equating $20 \%$ of the steam boiler capacity. This constraint addresses the limitations that steam boilers have in utilizing the excess flue gas from the combined cycles for power production.

In addition, the maximum combined electricity demand of the CCC and LNG plants is $15 \%$ of the steam boiler capacity (1800 MW), based on the steady-state results [27, 29. Finally, small penalization factors are applied to limit large variations that may show little incremental benefit and be undesirable in practice.

\section{Results and Discussion}

This section presents the results of the optimization of the integrated system. The results are for a case study with an LNG tank capacity of 8 million $\mathrm{kg}$. This tank capacity is selected based on the performance of the hybrid system because the overall trend of variables does not change with different tank sizes. As mentioned previously, all variables are presented in mass units to remain independent of the pressure and temperature conditions of the LNG tank. For typical LNG at the tank temperature and pressure of $-94{ }^{\circ} \mathrm{C}$ and 37 bar (LNG density is $290.6 \mathrm{~kg} / \mathrm{m}^{3}$ ), the standard capacity for the 8 million $\mathrm{kg}$ LNG inventory is $28000 \mathrm{~m}^{3}$, which is small compared to LNG tanks in commercial use and represents a very small incremental expense as a fraction of the overall CCC process and power plant.

Electricity demand and power production curves (Figure 5) show that a dynamic combination of power sources meets the power demand over time. Power production from coal combustion is the main source of power (with a potential capacity of $1800 \mathrm{MW}$ power generation) and the gas turbine is mainly used for peak-shaving. However, when wind power is available, less coal and gas power are produced and the required demand is met from all three resources. 

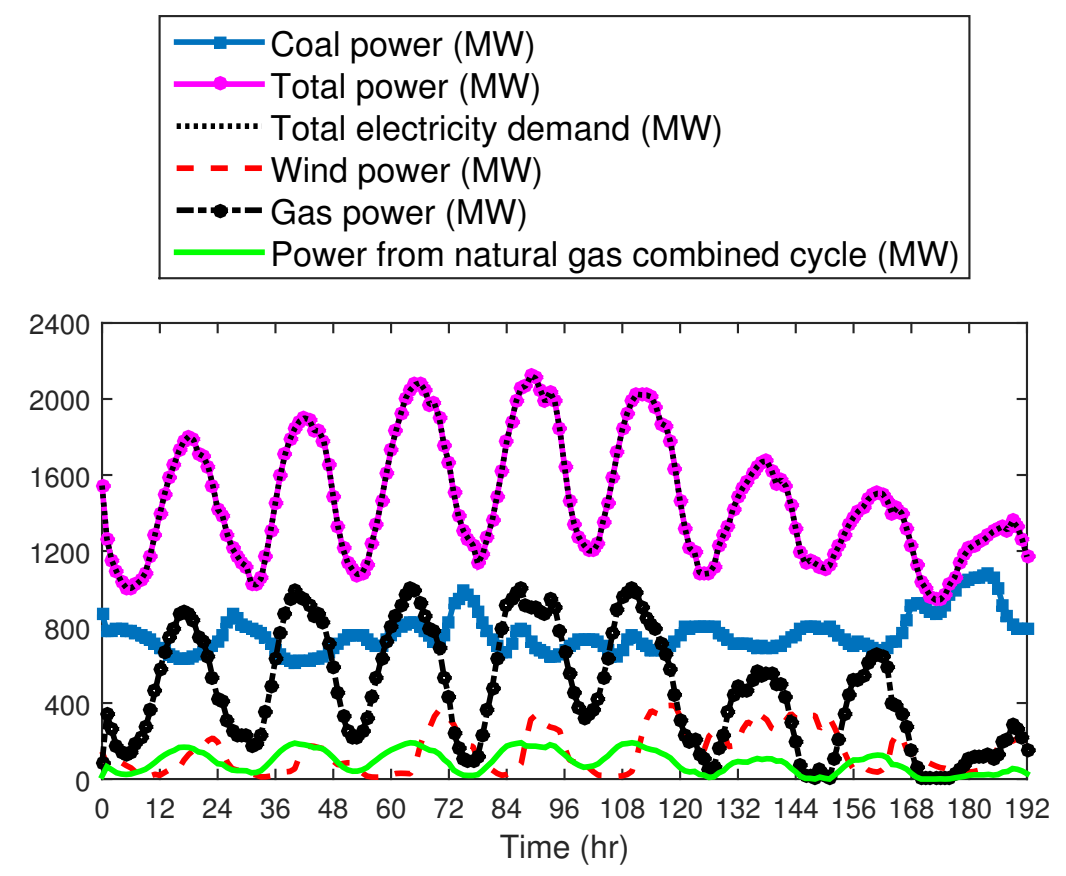

Figure 5: Electricity demand vs. power production

For a winter case when more wind is available, the wind power will have a significant contribution in meeting the total electricity demand [53. Power produced from natural gas combustion allows for a maximum power output of $1000 \mathrm{MW}$, though the power output from the turbine only reaches the maximum when electricity demand is at the maximum of the year (the middle four days). The heat content of the flue gas from gas turbine produces extra steam in the boiler. When the inefficiency of steam turbines is taken into consideration, the maximum steam produced as a result of the heat exchange of the flue gas is equivalent to $190 \mathrm{MW}$ of power during peak hours. Therefore, combustion of the vaporized LNG during peak hours compensates for the parasitic loss of the CCC and LNG plant and is able to deliver power up to $1190 \mathrm{MW}$.

While the maximum capacity for coal-based power generation is $1800 \mathrm{MW}$, variation limitations of the boiler, the economic advantages of natural gas power, and the intermittent generation from wind cause the optimized coal power pro- 
duction to stay below 1000 MW. This limited power production from coal is also because of the slow response of the boiler to ramp up to meet the peak demand. Relaxing the rate of change constraints on coal power leads to more power production from coal (not shown here). The maximum variation in the boiler load at any time step for the constrained case is less than $0.1 \%$ per minute (76 MW in an hour); thus, maximum variation in boiler load is much less than the assumed allowable change rate ( $7 \%$ per minute). The boiler also operates in the typical range of $45-100 \%$.

The dynamics of wind generation require a detailed discussion. This optimization technique looks both backward and forward in time, resulting in power dispatch that anticipates to some degree the future behavior of wind. Wind conditions can be accurately predicted about 24 hours into the future, with accuracy decreasing to near zero as time increases to about 72 hours. Unlike the quite predictable and mostly periodic total power demand, wind is neither predictable in the long term nor periodic, and the wind data here are both representative of quite different results on different days and of the time of day when wind is most available. Specifically, wind on average blows more during off-peak than during peak power demand. One of the great challenges of intermittent sources such as wind is to maximize its value and contributions on the grid even though 535 it contributes mostly during low-value periods and in inconsistent ways. These data show how the CCC process provides a synergy between wind and coal power that significantly benefits both processes.

Figure 6 better presents the trends of power production and electricity demand for the period between hours 36 and 80 (also shown in Figure 5). Between hours 36 and 60, it is seen from Figure 6 that integrated wind power is much less than that of hours 60 and 84 (approximately $50 \%$ less). The surge in wind power for the period between hours 60 and 84 would generally be known to a dispatcher by hour 36 . As indicated in the data, the amount of power produced from the coal boiler began to decrease a few hours prior to the wind coming 545 on line, with the energy storage component of the CCC making up the difference until the anticipated wind power had materialized. The energy storage 
of the CCC comes from the reduced parasitic load in the coal plant, which is not directly plotted but corresponds with the natural gas power production. In effect, the CCC process has moved the wind power and the stored energy in the LNG tank that was filled in the evening and night hours of the day before from a time of day when power demand is decreasing to near the peak power demand, optimizing its value on the grid both in economic terms and in $\mathrm{CO}_{2}$ reduction. In contrast, for the period between hours 36 and 60, when wind was not significant, the energy storage from the previous evening had to make up most of the power demand that the coal boiler could not provide, and coal power production remained high during a longer portion of the day.

This illustrates how the coal system with energy storing CCC can effectively move the wind power to peak demand when it is available and can compensate for a lack of wind when it is not sufficient, providing significant benefit to grid stability and to the economies of both systems. While it is not shown here, wind is generally shifted forward or backward in time to the nearest available peak in power demand, within a 24-hour window.

The LNG inventory, LNG production, and LNG requirement to run the CCC process with the electricity price appear in Figure 7. Natural gas flowing to and from the pipeline and electricity price appear in Figure 8. In this study, LNG inventory is initialized from a non-zero value because the integrated system of power generation and the CCC should be in operation throughout the year. Thus, at the beginning of the simulation, a non-zero initial value is appropriately selected for the LNG inventory, based on the pattern of this variable in subsequent days. Consequently, until there is inventory in the tank, LNG is supplied from it (LNG underproduction in Figure 7). Then, when electricity price is sufficiently cheap, natural gas is taken from the pipeline and stored in the LNG tank. As stated before, this is also the time when electricity demand is lower than at peak hours. Thus, LNG inventory in the tank increases (LNG 575 overproduction in Figure 7] during off peak times. It is seen in Figure 7 that a significant amount of natural gas is imported at hours 24, 72, and 144 and tank is completely filled up. This is because of the lower average power price at hours 

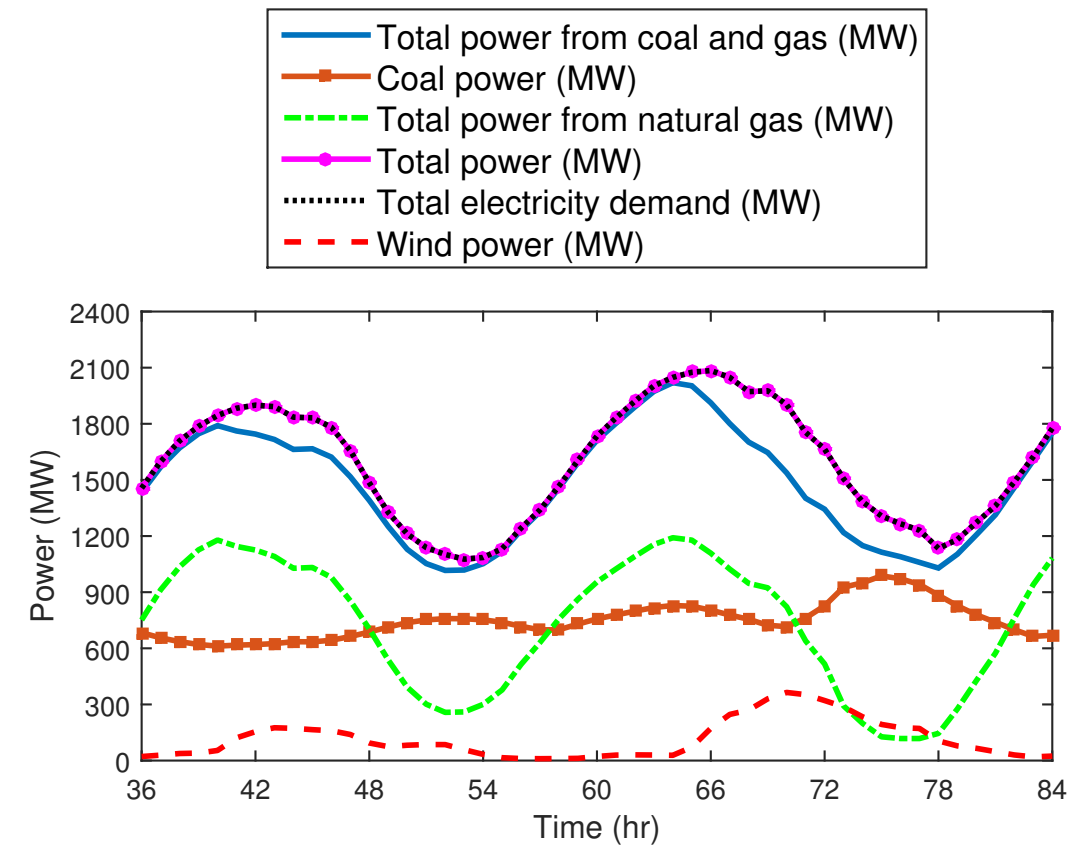

Figure 6: Increased value of wind power by using energy storage of the CCC

$24,72,144$ than the subsequent 48 hours. After tank is completely filled up in the early hours of the days starting at hours 24,72 , and 144, LNG is taken from the tank and the level of the tank drops until it reaches the low threshold of the tank. Unlike hours 24, 48, and 144 it is observed that at the beginning of hour 120, natural gas is imported as much as it can supply LNG for only the next 24 hours. Integrated wind power during the day starting at hour 120 is more than any other days in the time horizon (with respect to the integrated electricity demand). Because wind will help meet the demand, less LNG is needed in the tank in that day to supply sufficient cooling capacity through the peak. For other days, LNG tank fills completely because of the less available wind and more expensive power price.

Although the maximum power required to increase the pressure of the recirculating natural gas to the pipeline pressure is approximately $3.2 \mathrm{MW}$, it is still more economical (though not more energy efficient) to export a fraction of the 

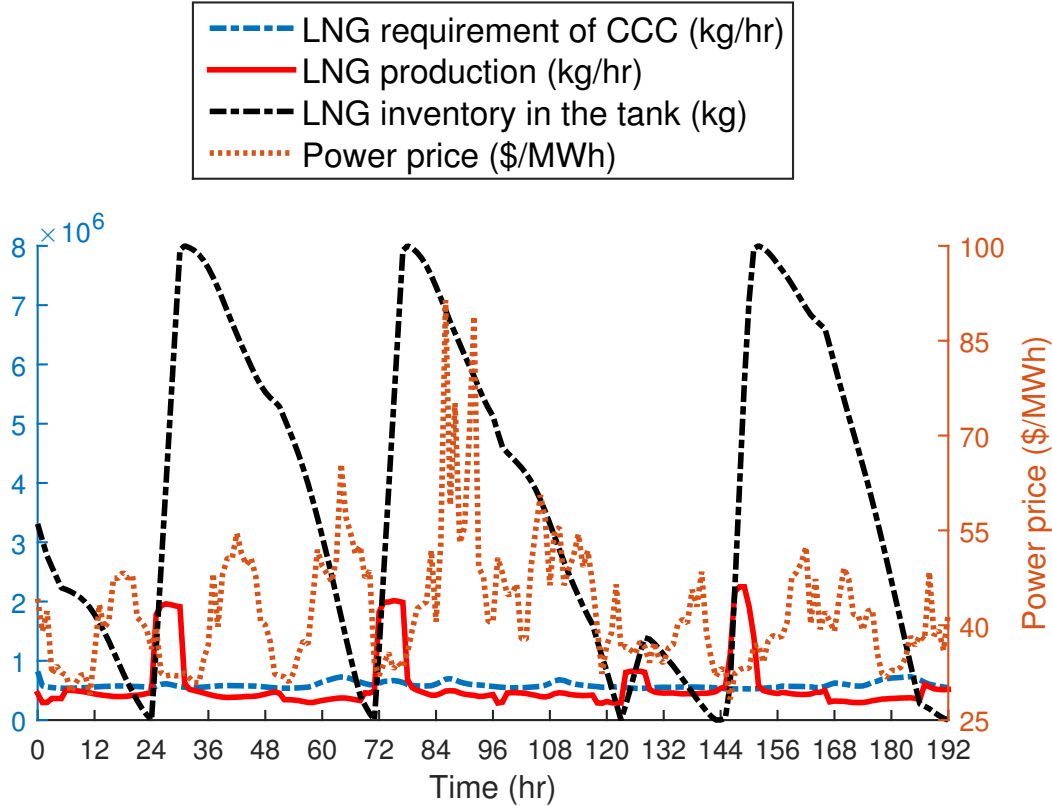

Figure 7: LNG inventory, LNG production, and LNG required to run the CCC vs. power price

more pure natural gas to the pipeline until the electricity price is comparatively low. In the cases where the export of natural gas is not considered an option, the trend of other variables remain the same but the profit obtained over the entire time horizon decreases by $16.6 \%$ when compared to cases where the export of natural gas is considered. Mixed refrigerant compressors should also remain in operation during peak hours to process natural gas that could have otherwise been exported to the pipeline. Therefore, more power should be produced to meet the loss of the mixed refrigerant compressor. The aforementioned facts also illustrate the advantage of using LNG as a refrigerant in the CCC process as it can be exported to the pipeline when it is vaporized in the CCC process. Vaporized LNG also serves as a fuel when it is needed to produce more power in the gas turbine.

It is also important to mention that the exported natural gas shown in Figure 

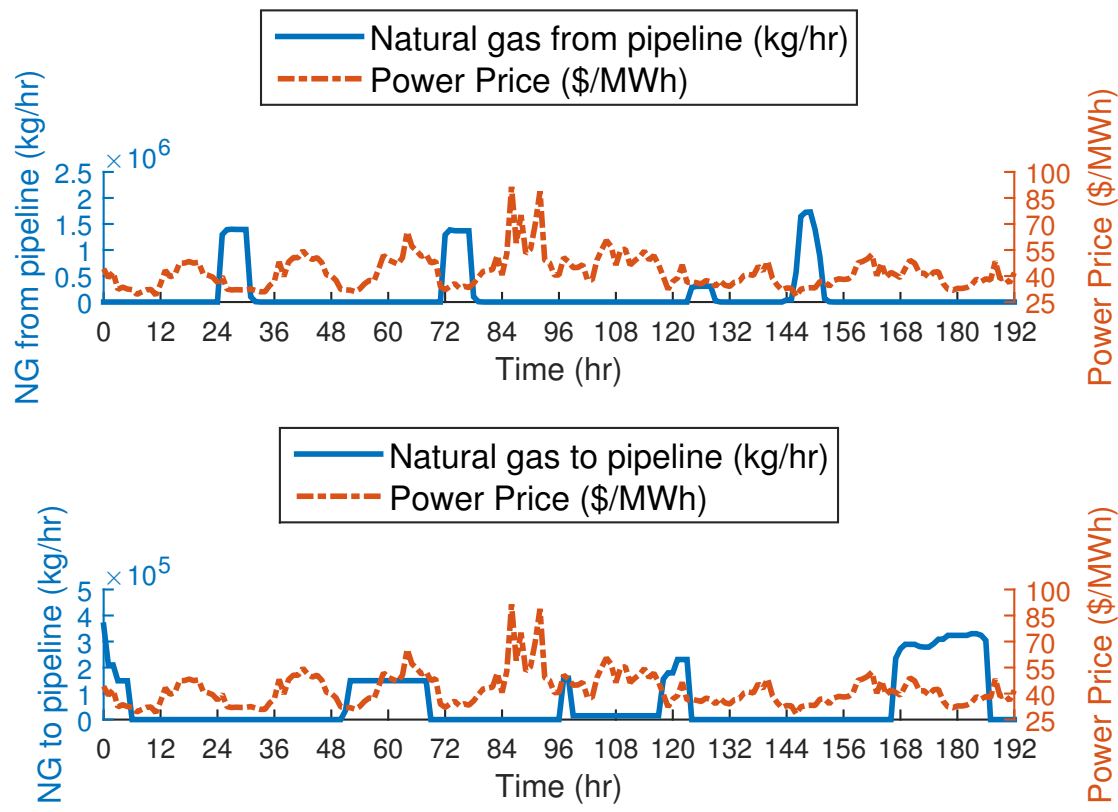

Figure 8: Natural gas imported and exported vs. power price

605 LNG inventory, the initial value of the exported natural gas is selected according to the pattern of this variable in the following days. Because the electricity price is not sufficiently low, a fraction of the vaporized LNG is exported to the pipeline. The export of natural gas continues until the electricity price reaches 610 hybrid system is driven by the stored LNG until it reaches the low threshold in early hours of the next day. Depending on the power price, this general trend in LNG inventory (Figure 7) and natural gas imported and exported (Figure 8) cycles regularly. This is typical for an integrated system with energy storage capability. This cyclical nature is based on the ongoing need for electricity which, in return, requires natural gas and LNG for flue gas treatment in the CCC process.

Electricity on-site demand curves for the main electricity consuming com- 
ponents of the system provide additional insight. The demand curves for the natural gas compressor, mixed refrigerant compressor, and CCC plant (Figure 9) illustrate the dynamics of the plant. The natural gas compressor and CCC plant depend on the residential electricity demand because more power should be produced during peak hours, which in turn produces more flue gas. Therefore, the CCC plant demand also increases during peak hours. However, Figure 5 shows that more power is produced from natural gas during peak hours. Because natural gas combustion emits less $\mathrm{CO}_{2}$, less LNG is required when compared to the case where coal is combusted to meet the same amount of electricity demand. Thus, during peak hours, the natural gas compressor has lower electricity demand than in off-peak hours when coal is the main source of power production. 630 On the other hand, the mixed refrigerant compressor demand decreases when electricity is expensive as most of the required LNG is taken from the tank. This is the main energy storing aspect of CCC; the parasitic load associated with the CCC-based carbon capture can be partially or completely met with stored LNG. An insignificant residual flow remains to maintain spinning turbomachinery and temperature profiles. When LNG is stored in the tank and power demand is high, it is economical to curtail the mixed refrigerant compressor and transfer the saved electricity to meet the peak demand. When there is no storage tank, power should also be supplied to compensate for the loss of the mixed refrigerant compressor and to meet the LNG requirement during peak hours. ${ }_{640}$ A comparison between power demand of the mixed refrigerant compressor with and without energy storage is shown in Figure 10. The efficiency loss associated with working at a different load than the designed case in the operation of the mixed refrigerant compressor is not considered in this study and should be addressed in future work.

${ }_{645}$ The average profit acquired from the integrated system is approximately $\$ 35 \mathrm{k} / \mathrm{hr}$. While the annual performance of the hybrid system over a longer time frame is needed, it is expected that the profit obtained from this hybrid system is sufficiently large to pay a significant fraction of the cost of construction of the cryogenic carbon capture plant. Performance of the system over a longer time 


- Mixed refrigerant compressor demand (MW)
- CCC plant demand (MW)
$-\ldots-$ Natural gas compressor demand (MW)
........ Power Price $(\$ / M W h)$

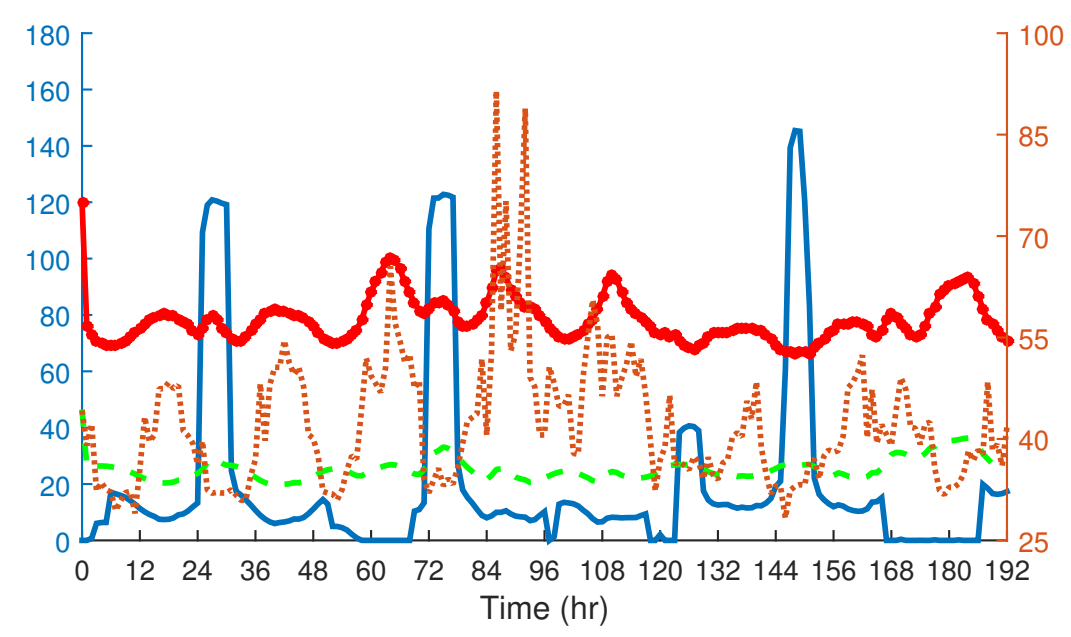

Figure 9: Demand curves for natural gas compressor, mixed refrigerant compressor, and CCC plant

horizon is the subject of future work.

\subsection{Sensitivity analysis}

Finally, the effects of the penalization factors applied in this study are investigated. Penalization factors influence the optimization outcome and are adjustable parameters to obtain simulation results that are satisfactory based on operator feedback. These factors serve as tuning factors to the model to smooth the trend of the variation of the simulated operation. If movement penalization is not applied, large and sharp variations in the trends of variables creep into the solution with little additional benefit towards the overall objective. This movement contrasts with the desired stability of the system and highlights the need to include additional terms in the optimization problem to align simulation objectives with operational experience. However, it is important to minimize the 


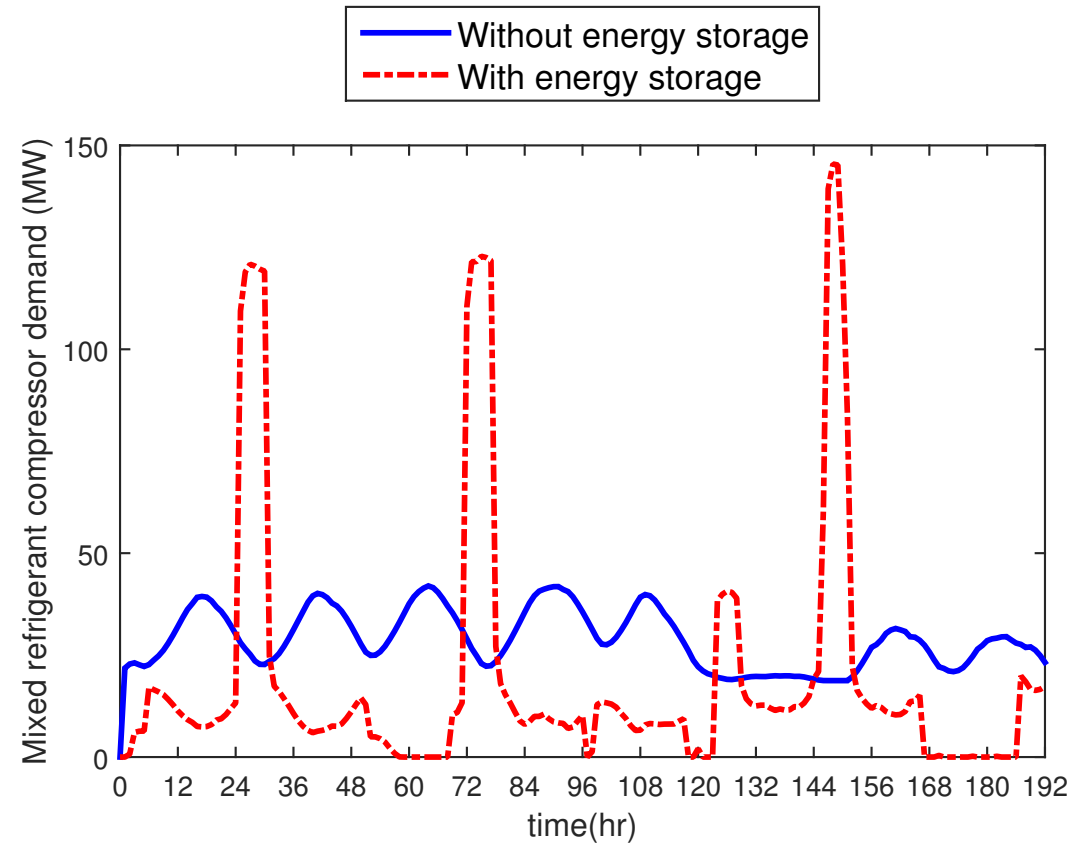

Figure 10: Comparison between power demand of mixed refrigerant compressor with and without energy storage

use of penalization factors as much as possible because they impose an artificial cost to the objective function. A penalization factor is applied to the flow rate of the imported and exported natural gas. The change in the objective function for applying different penalty factors for these variables is less than $5 \%$ for one order of magnitude of variation. In other words, these penalization factors do not change the overall trend of the variables over the time horizon, and the main effect the factors have is on the smoothness of the results. These tuning factors are adjusted in each simulation when sharp fluctuations are observed in the trend of the decision variables from initial attempts to solve the problem.

\section{Conclusion}

This paper reports an optimization framework for the integrated system of fossil and renewable energy sources with the Cryogenic Carbon Capture ${ }^{\mathrm{TM}}$ 
(CCC) process. The CCC process is a post-combustion method for $\mathrm{CO}_{2}$ removal

to store excess energy in the form of condensed, cold refrigerant. These features enable the power grid to utilize more renewable energy sources. The objective in this study is to meet the total electricity demand of a residential area and the CCC process and to maximize the operating profit of the system.

Results show that a combination of coal, gas, and wind generation can be fully utilized to meet the total electricity demand. Produced $\mathrm{CO}_{2}$ from the fossil-fueled power plants is captured at a rate of $90 \%$ while $100 \%$ of the available wind power is utilized. The sporadic wind production is effectively moved from periods of low value to the grid to periods of peak value while significantly stabilizing the grid. Off-peak excess generating capacity also moves to peak periods, increasing capital utilization and decreasing the fluctuation in boiler loads relative to the fluctuation of power demand. While the steam boiler considered in this study is assumed to follow the electricity demand curves in a change rate as much as $7 \%$ per minute, the maximum rate of load change in the boiler is observed to be less than $0.1 \%$ per minute. The average profit acquired from the hybrid system is approximately $\$ 35 \mathrm{k} / \mathrm{hr}$.

Future work should address the effects of the equipment capital cost in the economic evaluation of the integrated system. Also, the integrated system performance should be considered for baseline steam boilers that are not able to follow the electricity demand curves. Further directions for future studies include the application of the proposed system for smart grid integration, investigation of the effect of the recirculation system on the flue gas exhausts from coal and gas-fired power plants, consideration of the efficiency loss of the compressors working at non-optimal operating mode, simulating the performance of the hybrid system over a longer time frame, and exploring the uncertainty in prices and wind data. 


\section{Acknowledgments}

The authors are grateful for the financial support and technical cooperation from Sustainable Energy Solutions (SES), without which this work could not

working on the Cryogenic Carbon Capture process ${ }^{\mathrm{TM}}$, who provided essential energy and engineering data.

\section{References}

n [1] International Energy Agency, Key world energy statistics, http://www .

[2] Y. Wang, F. Ronilaya, X. Chen, A. P. Roskilly, Modelling and simulation of a distributed power generation system with energy storage to meet dynamic household electricity demand, Appl. Therm. Eng. 50 (1) (2013) 523 - 535. doi:10.1016/j.applthermaleng.2012.08.014.

715 [3] Global Emissions by Source, http://www.epa.gov/climatechange/ ghgemissions/global.html, (accessed November 2014).

[ [4] Overview of greenhouse gases, http://www.epa.gov/climatechange/ ghgemissions/gases/co2.html, (accessed November 2014).

[5] Trends in global $\mathrm{CO}_{2}$ emissions, Tech. rep., 720 attp://edgar.jrc.ec.europa.eu/news_docs/ pbl-2013-trends-in-global-co2-emissions-2013-report-1148.pdf, (accessed November 2014).

[6] L. Göransson, F. Johnsson, Dispatch modeling of a regional power generation system - Integrating wind power, Renew. Energ. 34 (4) (2009) 1040 1049. doi:10.1016/j.renene.2008.08.002.

[7] E. D. Delarue, P. J. Luickx, W. D. D'haeseleer, The actual effect of wind power on overall electricity generation costs and $\mathrm{CO}_{2}$ emissions, Energ. 
730

Convers. Manage. 50 (6) (2009) 1450 - 1456. doi:10.1016/j.enconman. 2009.03 .010

[8] E. Hu, Y. Yang, A. Nishimura, F. Yilmaz, A. Kouzani, Solar thermal aided power generation, Appl. Energ. 87 (9) (2010) 2881 - 2885. doi:10.1016/ j.apenergy.2009.10.025.

[9] F. Manenti, Z. Ravaghi-Ardebili, Dynamic simulation of concentrating solar power plant and two-tanks direct thermal energy storage, Energy 55 (2013)

$73589-97$. doi:10.1016/j.energy.2013.02.001.

[10] K. M. Powell, J. D. Hedengren, T. F. Edgar, Dynamic optimization of a solar thermal energy storage system over a 24 hour period using weather forecasts, in: American Control Conference (ACC), 2013, IEEE, 2013, pp. $2946-2951$.

[11] K. M. Powell, J. D. Hedengren, T. F. Edgar, Dynamic optimization of a hybrid solar thermal and fossil fuel system, Solar Energy 108 (0) (2014) 210 - 218. doi:http://dx.doi.org/10.1016/j.solener.2014.07.004.

[12] O. Onar, M. Uzunoglu, M. Alam, Dynamic modeling, design and simulation of a wind/fuel cell/ultra-capacitor-based hybrid power generation system, J. Power Sources 161 (1) (2006) 707 - 722. doi:10.1016/j.jpowsour. 2006.03 .055

[13] C. A. Kang, A. R. Brandt, L. J. Durlofsky, Optimal operation of an integrated energy system including fossil fuel power generation, $\mathrm{CO}_{2}$ capture and wind, Energy 36 (12) (2011) 6806 - 6820. doi:10.1016/j.energy. 2011.10 .015

[14] B. Belaissaoui, G. Cabot, M.-S. Cabot, D. Willson, E. Favre, $\mathrm{CO}_{2}$ capture for gas turbines: an integrated energy-efficient process combining combustion in oxygen-enriched air, flue gas recirculation, and membrane separa-

口 tion, Chem. Eng. Sci. 97 (2013) 256 - 263. doi:10.1016/j.ces.2013.04. 755 027. 
[15] H. Chalmers, M. Leach, J. Gibbins, Built-in flexibility at retrofitted power plants: What is it worth and can we afford to ignore it?, Energy Procedia 4 (2011) 2596 - 2603. doi:10.1016/j.egypro.2011.02.158.

[16] S. M. Cohen, G. T. Rochelle, M. E. Webber, Optimizing post-combustion $\mathrm{CO}_{2}$ capture in response to volatile electricity prices, International Journal of Greenhouse Gas Control 8 (2012) 180-195. doi:10.1016/j.ijggc. 2012.02.011

[17] S. M. Cohen, G. T. Rochelle, M. E. Webber, Optimal operation of flexible post-combustion $\mathrm{CO}_{2}$ capture in response to volatile electricity prices, Energy Procedia 4 (2011) 2604-2611. doi:10.1016/j.egypro.2011.02.159

[18] S. M. Cohen, G. T. Rochelle, M. E. Webber, Turning $\mathrm{CO}_{2}$ capture on and off in response to electric grid demand: A baseline analysis of emissions and economics, ASME Journal of Energy Resources Technology 132 (2010) 021003. doi:10.1115/ES2008-54296

[19] S. Ziaii, S. Cohen, G. T. Rochelle, T. F. Edgar, M. E. Webber, Dynamic operation of amine scrubbing in response to electricity demand and pricing,

口 Energy Procedia 1 (1) (2009) 4047-4053. doi:10.1016/j.egypro.2009. 02.211

[20] H. Chalmers, J. Gibbins, Initial evaluation of the impact of postcombustion capture of carbon dioxide on supercritical pulverised coal power plant part load performance, Fuel 86 (14) (2007) 2109 - 2123. doi:10.1016/j.fuel.2007.01.028

[21] H. Gerbelová, P. Versteeg, C. S. Ioakimidis, P. Ferrão, The effect of retrofitting Portuguese fossil fuel power plants with CCS, Appl. Energ. 101 (2013) 280 - 287. doi:10.1016/j.apenergy.2012.04.014.

[22] C.-C. Cormos, Integrated assessment of IGCC power generation technology with carbon capture and storage CCS, Energy 42 (1) (2012) 434 - 445. doi:10.1016/j.energy.2012.03.025. 
[23] C.-C. Cormos, P. S. Agachi, Integrated assessment of carbon capture and

[24] Z. Khorshidi, M. T. Ho, D. E. Wiley, Techno-economic evaluation of using biomass-fired auxiliary units for supplying energy requirements of $\mathrm{CO}_{2}$

[25] A. R. Mohan, U. Turaga, V. Subbaraman, V. Shembekar, D. Elsworth, S. V. Pisupati, Modeling the $\mathrm{CO}_{2}$-based enhanced geothermal system

[28] Impact of Load Following on Power Plant Cost and Performance: Literature Review and Industry Interviews, DOE/NETL-2013/1592, Tech. rep.

[29] M. Jensen, Energy Processes Enabled by Cryogenic Carbon Capture, Ph.D. thesis, Brigham Young University (2015).

[30] L. L. Baxter, Carbon dioxide capture from flue gas, US Patent App. 12/745,193 (Sep. 22 2011). 
[31] L. L. Baxter, Systems and methods for integrated energy storage and cryogenic carbon capture, WO Patent App. PCT/US2012/061,392 (May 2 2013).

[33] S. M. Safdarnejad, J. Gallacher, J. D. Hedengren, Dynamic optimization for

[37] J. D. Hedengren, J. L. Mojica, W. Cole, T. F. Edgar, APOPT: MINLP Solver for Differential Algebraic Systems with Benchmark Testing, INFORMS Annual Meeting (2012).

[38] A. Wächter, L. T. Biegler, On the Implementation of a Primal-Dual 835 Interior Point Filter Line Search Algorithm for Large-Scale Nonlinear 口 Programming, Math. Program. 106 (1) (2006) 25-57. doi:10.1007/ s10107-004-0559-y.

[39] S. M. Safdarnejad, T. Hall, J. D. Hedengren, L. L. Baxter, Dynamic optimization of cryogenic carbon capture with large-scale adoption of renewable 
power, in: Proceedings of the American Institute of Chemical Engineers (AIChE) Conference, Atlanta, GA, 2014.

[40] M. Utamura, S. Hoizumi, Y. Takeda, T. Sasaki, H. Komatsu, Kirikami, et al., Gas turbine exhaust recirculation method and apparatus, US Patent 6,202,400 (Mar. 20 2001).

[41] F. Liu, G. J. Smallwood, H. Guo, The chemical effect of $\mathrm{CO}_{2}$ replacement of $\mathrm{N}_{2}$ in air on the burning velocity of $\mathrm{CH}_{4}$ and $\mathrm{H}_{2}$ premixed flames, Combust. Flame 133 (2003) 495-497. doi:10.1016/S0010-2180(03)00019-1.

[42] J. E. Hustad, P. E. Røkke, Exhaust Gas Recirculation in Gas Turbines for Reduction of $\mathrm{CO}_{2}$ Emissions; Combustion Testing with Focus on Stability and Emissions, International Journal of Thermodynamics 8 (2005) 167-173.

[43] California Independent System Operator (CAISO), System Demand, Wind and Solar Forecast, http://oasis.caiso.com (accessed February 2015).

[44] California Independent System Operator (CAISO), System Demand, CAISO Demand Forecast, http://oasis.caiso.com/, (accessed February 2015).

[45] S. M. Safdarnejad, J. D. Hedengren, L. L. Baxter, Effect of cryogenic carbon capture (CCC) on smart power grids, in: Proceedings of the American Institute of Chemical Engineers (AIChE) Conference, Austin, TX, 2015, p. accepted.

[46] LCG consulting website, http://www.energyonline.com/Data/ GenericData . aspx?DataId=20\&CAISO_-_Average_Price, (accessed February 2015).

[47] Cost and Performance Baseline for Fossil Energy Plants Volume 1: Bituminous Coal and Natural Gas to Electricity, Tech. rep., National Energy Technology Laboratory (NETL) (2010). 
[48] M. Berkenpas, E. Rubin, C. Zaremsky, User manual: Integrated Environmental Control Model. Carnegie Mellon University, http://www.cmu.edu/epp/iecm/.

[49] U.S. Energy Information Administration (EIA), http://www.eia.gov/ coal/news_markets/, (accessed November 2014).

[50] U.S. Energy Information Administration Natural Gas Monthly Report, http://www.eia.gov/naturalgas/monthly/pdf/table_03.pdf, (accessed February 2015).

[51] J. Lindsay, K. Dragoon, Summary Report on Coal Plant Dynamic Performance Capability, Tech. rep., Renewable Northwest (2010).

[52] S. M. Safdarnejad, J. D. Hedengren, N. R. Lewis, E. Haseltine, Initialization strategies for optimization of dynamic systems, Computers and Chemical Engineering (2015) submitted.

[53] S. M. Safdarnejad, L. Kennington, J. D. Hedengren, L. L. Baxter, Investigating the impact of cryogenic carbon capture on the performance of power plants, in: Proceedings of the American Control Conference (ACC), Chicago, IL, 2015, p. accepted. 